\title{
Professional Thinking Formation Features of Prospective Natural Science Teachers Relying on the Competence-Based Approach
}

\author{
Suriya I. Gilmanshina ${ }^{1}$, Rimma N. Sagitova ${ }^{1}$, Svetlana S. Kosmodemyanskaya ${ }^{1}$, Fidaliya D. Khalikova ${ }^{1}$, \\ Natalia G. Shchaveleva ${ }^{1}$, Gulnar F. Valitova ${ }^{1} \&$ Natalia S. Motorygina ${ }^{1}$ \\ ${ }^{1}$ Kazan (Volga region) Federal University, Kazan, Russia \\ Correspondence: Suriya I. Gilmanshina, Kazan (Volga region) Federal University, Kremlyovskaya Street 18, \\ Kazan, 420008, Russia. E-mail: gilmanshina@yandex.ru
}

Received: January 17, 2015 Accepted: January 29, 2015 Online Published: February 26, 2015

doi:10.5539/res.v7n3p341 URL: http://dx.doi.org/10.5539/res.v7n3p341

\begin{abstract}
This paper experimentally proved and implemented a specific approach to designing a control system for formation and development of professionally oriented thinking of students - future teachers of physics, chemistry and biology. Specific methods for regulating the control and self-control of the progress of its development have been proposed, developed in the logic of the educational process in a pedagogical higher school and directed to achievement of educational goals. The primary means of forming professionally oriented thinking in the unity of its procedural, substantive and operational components is to optimize the educational process of higher school through the implementation of the objectives arising from the peculiarities of professional thinking of a teacher. The contents of this article are of value to teachers of physics, chemistry and biology, as well as to future teachers.
\end{abstract}

Keywords: professional thinking, teachers, prospective natural science, competence-based approach

\section{Introduction}

Formation of professional thinking is inseparable from this historical period in the development of humanity and science, including teaching. The modern period in the history is characterized by its inherent specific ideals of scientific cognition and methodological approaches to understanding reality. The previous theory of teaching and educating a person of "a certain type", based on domination of classical—rigidly determinate — style of thinking, came into conflict with the new goals of social development: formation of a man as a creative personality. That is a modern problem situation is such that it became necessary to move to the non-classical ideas, synergetic vision of the world and the events taking place in it and, as a consequence - the need to build a pedagogical system of forming future teachers' professional thinking on the basis of the today's realia (Danilov, 2005; Gil'manshina, 2005; Kashapov, 2000; Kulyutkin, 1986; Ivanov et al., 2015; Fayzullina \& Mukhametzyanova-Duggal, 2015; Mrathuzina et al., 2015).

\subsection{Factors Causing the Need for Forming Professional Thinking of Future Teachers}

Let us name the major factors, causing the development of education today and the need to form professional thinking in the future teachers on the basis of competence-based approach. First, the modern historical epoch is characterized by a special education model, focused on a creative initiative, independence, competitiveness of future professionals, including teachers (Federal Law "On Education", the Concept of modernization of national education for the period up to 2010). Creativity of a teacher depends on the degree of development of his professional thinking. Professionally oriented thinking initiates a reflexive activity of a teacher, giving him the opportunity to become a professionally active teacher, capable of independent innovative activity, and as a result - to be in demand and competitive.

Second, the increase in the theoretical level of the disciplines' content has led to the aggravation of contradictions between the general goals of education and the real possibilities of the prospective teachers to solve applied problems.

Third, in the system of school education there have been dramatic changes: diversification, enrichment of school practice by new educational technologies, forms of teaching, ability to independently choose learning and teaching base. However, according to numerous observations of teachers, there is often the inability of young 
teachers to show independence and to creatively apply theoretical knowledge acquired in university, in school practice. This fact complicates the self-educative process of beginning teachers. Today there is a need for a teacher having a good command of modern teaching methods of subjects in order to form students' key competencies and readiness for implementation of independent cognitive activities (educational competency, involving the accumulation of integrated knowledge and its application in practice).

Currently, in a number of teacher education universities in the classes of teacher training cycle subjects and of private methods, a special work on the formation of students' professional thinking is carried out, there are workshops on training future teachers for the solution of pedagogical problems, appropriate programs of specialized courses are being developed (Matyushkin, 2003; Vygotsky, 2005; Polyakov, 2003; Sakhieva et al., 2015; Merzon et al., 2015; Levina et al., 2015). The feasibility of this vision of the educational process is obvious. But there is not enough theoretical generalization of this experience in the literature.

All this makes it necessary to search for new approaches to the formation of students' professional thinking, developing questions on the essence, features, structure and functions of professional thinking of the subject teachers, as well as a complete picture of forming it in reliance on the competence-based approach.

\section{Methodological Framework}

Methodological basis for investigating this problem was the competence-based approach, the essence of which is that it cannot be narrowed down to only a knowledge-orienting component. Competence, from our point of view, as the ability of an individual and the social-professional characteristic of a human-citizen, includes relevant knowledge, skills, ways of thinking, reflection, self-awareness, and is characterized by a degree of mastery of specific competencies. We define a competency as an aspect of professional activity, which is necessary to be formed in professional education institutions. The competence-based approach relates generally to the educational purpose and result, which, in turn, determine its contents. As priority ones there are the defined principles of humanization and humanitarization of education, diversification, fundamentalization, integration, as well as the principle of innovative professional activities. The most popular are the self-regulated learning technologies, the educational and the information-communication technologies.

Analysis of national practice of developing the competence-based approach has shown unreasonableness of its opposition to the knowledge-based one. Without denying the fundamental role of knowledge, it requires the formation of productive use of abilities. Focused on the formation of spiritual-semantic sphere of a personality of a future expert the competence-based approach acquires a humanistic orientation. Enhancement of the value-semantic component of specialist activities on the basis of the competence-based approach contributes to the formation of a new worldview as a way of life, as a way of thinking. Professional thinking as a necessary quality of a person for any specialist is becoming one of the key professional competencies (Shelontsev, 2000; Korzhuev, 2002; Meshkov, 2003; Sibgatova et al., 2015; Khairullina et al., 2015).

The essential components of a pedagogical competence of a teacher are the general cultural, general pedagogical, socio-communicative, special-subject, methodical competences and an auto-competence that overlap and mutually complement each other. The competence model of a teacher of natural sciences includes key competences or key skills of meta-subject character, sociocultural, general-pedagogic (or methodological), subject-oriented competences. Subject-oriented competences, integrating the special-subject (in the field of the taught natural science discipline) and the methodological competences express strengthening of applied character of teacher education, the implementation of the educational potential of each particular discipline. This is a set of competencies in the field of training activities, including elements of the logical, methodological, all-educational activity correlated with real objects in natural science.

Pedagogical competence of a teacher of natural sciences as an integral personality formation cannot be the result of a specific educational technology and requires the development of technologies for forming professional thinking in a system of several components, which means the formation of scientific-logical and development of intuitively-creative aspects of thinking, development of the unity of theory and practice knowledge components (Gilmanshin, 2008; Gromyko, 2000; Gilmanshina \& Kamasina, 2013).

Professional (professionally oriented) thinking is not seen in a narrow professional aspect, but as the most important personal quality necessary for any specialist (professional orientation of a personality is understood as a personal quality and, speaking about professional orientation, the formation of a personality is suggested). "Key competencies are based on such personality qualities as independent thinking, the ability to analyze and synthesize, creativity, critical thinking ..." (Mukhametzyanova, 2006). Professional thinking integrates these qualities, therefore, is one of the key competencies. According to the activity-based approach the primary is the manifestation of such a competence part as readiness for meaningful implementation of certain activities. A 
teacher's professional thinking allows carrying out intelligently and independently the basic types of pedagogic activities (teaching, educational, organizational-communicative, research). Hence, it, as an important quality of a personality, is a key competency of a teacher and one of the main characteristics of his pedagogical competence.

Professional thinking as a component of general human culture has a deep humanity basis. This means that the highest level of its formation (creative skills of a natural sciences teacher) cannot be achieved without general education in humanities, without integration of natural science and humanities education and its fundamentalization, without innovative approaches to problem solving (Gilmanshina \& Motorygina, 2013).

Professional thinking is generic in relation to the whole group of the forms of thinking noted in literature, associated with a particular occupation or groups of occupations: pedagogical, legal, mathematical, et cetera. Its specificity is manifested in the activities and determined by the content of objectives, problem situations being solved by a professional in various stages of his career path. This is the content side of professional thinking.

Depending on the subject being taught by an educator, on its specific role in the education system, the problem of deeper specialization of pedagogical thinking is solved. Professional thinking in its practical orientation in accordance with the nature of the activity - is an essential element of the teaching profession mechanism. It provides the interconnectedness and interdependence of the major types of educational activities (training, educative, organizational-communicative and scientific research). Therefore, from the perspective of the key features of teaching activities (study of a student's personality, creating motivation, determination of the objective, the content selection, search for pedagogical tools relevant to the objective, and the result reflection) professional thinking can be considered on the basis of the competence-based approach as a core teacher's competency of humanistic, sociocultural, and value orientation.

Analysis of the sources shows that in recent years the interest in the problem of forming professional thinking has greatly increased. The models of teacher professional thinking are being elaborated. The designed by Osipova (2011) generalized model of teacher professional thinking is represented as a special case of practical thinking, its level of formation is defined by the coefficient of professionalism. Kashapov (2000) (associates the structure of professional thinking with the highest forms of practical thinking. In the models of other scholars Kulyutkin (1986), Goryunova (1981) and Markova (2007) the intellectual component of thinking is mainly mentioned. In the real educational process the abstracting of any of professional thinking components seems to us as inappropriate.

Study of the problem of a teacher's professional thinking has revealed that at present there is no stable system in the science, which defines the understanding of the laws of formation and functioning of professional thinking of a natural sciences teacher. Important is a new perspective on a teacher's thinking as a key and core competency of the educator that requires the development of issues on the essence, features, structure and functions of professional thinking of a teacher-naturalist in reliance on the competence-based approach.

The competence-based approach requires the formation and use of ability to creativity and teacher's self-development. Therefore, the following understanding of the essence of pedagogical thinking is of interest. Pedagogical thinking is a specific mental activity of educators-scientists and teachers, in the course of which the reflection and creative transformation of training and education phenomena are happening in their mentality as social functions, as well as a subjective designing of the educational process in accordance with the social objectives of education (Vilkeev, 1992, 2001).

The peculiarity of a teacher's professional thinking is caused by the specifics of functions of this thinking. When performing some functions a teacher's thinking is intuitive and practically-situational, in the performance of others-exploratory and even theoretical. The definition stated by D. V. Vilkeev most adequately captures the essence of the "professional thinking of a teacher" concept, and further on we are going to rely on it (Vilkeev, 1986). Professional teacher thinking - is a specific mental activity, during which there is a generalized reflection and creative transformation in his mind of the objective characteristics of the pedagogical process, modeling of the training and education processes, stipulated by the specifics of pedagogical phenomena, goals and objectives of training and education, as well as by the professional experience of a teacher.

Professional thinking of a teacher of natural science subjects has its characteristics, specific structure and ways of its development, conditioned by the peculiarities of the competent educator activities in teaching a particular school subject, in forming the scientific outlook and logical culture of students. The peculiarity of the competent professional teacher activity, related to the specifics of the taught subject, is most evident in his didactic activity - explaining the essence of natural science phenomena, theories, laws, involving environmentally sound experiments. 
Consideration of a teacher's thinking as an educator's core competency helped establish the following. There are its seven basic functions allocated: explanatory, diagnostic, prognostic, projective, reflexive, teaching process management and communicative (the first five can be attributed to the forms and methods of scientific thinking). The essence of professional thinking of a teacher-naturalist is manifested in synergetic effect of unity of the especial-scientific (thinking in the subject of specialization area), pedagogical (scientific and applied) and methodical thinking. Its peculiarity is related to the characteristics of thinking in the field of a teacher's subject specialization.

In order that a prospective teacher from the ordinary level of thinking passed on to the scientific one, it is required to induce him to use scientific knowledge in dealing with both pedagogical and natural science exercises, which requires a certain system of logic problems. Logical problems on natural sciences encourage students to use their existing scientific knowledge in the analysis of problem situations, used as a means of developing scientific thinking. Further on, when studying at a university, as a result of implementing the systemic, holistic, personal and activity-based methodological approaches, the striving for scientific knowledge of any phenomena in the natural sciences and pedagogy is being formed in the prospective teachers.

The structure of teacher thinking includes knowledge and ways of knowing, which he/she operates systematically. For a teacher-naturalist it is significant to master the methodology of natural science knowledge. The analysis of scientific cognition in the natural sciences allowed revealing technologies for forming scientific thinking: teaching scientific description, explanation, experimentation, the transformation of its results, the integration of knowledge. The didactic conditions of implementing these technologies are: 1) formation of a logical culture of a specialist's personality; 2) empowering with the methods of scientific knowledge; 3) formation of scientific worldview principles and outlooks on natural science objects and processes.

The implementation of the competence-based approach in higher teacher education (taking into account its main mission - the strengthening of the practical orientation of education) requires attention to the formation of the subject-oriented aspect of teacher thinking (thinking in the field of subject specialization). Its peculiarity is mainly due to the specifics of existence forms of a matter (physical, chemical, biological), peculiarity of natural science knowledge, its structure and the specifics of professional activity. These features should definitely develop; manifest themselves in a competent performance and in prospective teachers of natural science.

Consideration of professional thinking as one of the main characteristics of pedagogical competence of a teacher suggests that a teacher-naturalist thinks not only with consideration for the specifics of natural science phenomena knowledge. A teacher, using the principles of didactics, should establish the process of explaining the natural science phenomena in the classroom and ensure the acquisition of the essence and concepts by the students. Evident is a relationship of special-scientific thinking with pedagogical, which determines the complementation of scientific thinking in the field of subject specialization by the "scientific-pedagogical thinking" concept.

Scientific-pedagogical teacher thinking has its specific features, one of which is caused by the specifics of the taught science field. A certain subject as if "dictates" a way for comprehending it, and knowledge of special material (on physics, chemistry, biology) becomes a form of thinking. Scientific thinking in the field of a teacher's subject specialization predetermines the presence of the abilities to apply the scientific theory as a method for solving subject problems and the availability of certain intellectual skills such as the ability to analyze, synthesize, to draw an analogy, and others. The general regularities of scientific thinking, scientific-research, and general methods of scientific research logic provide a teacher's insight into the process and methods of natural science objects knowledge, as well as allow him to determine the logic and methods for describing and explaining these objects when presenting the scientific knowledge. This requires consideration of the scientific-pedagogical aspect of professional thinking of a teacher-naturalist through the prism of the interrelation of logical culture of a personality, logic and methods of the taught science and functions of pedagogical thinking. A teacher, while explaining the educational material in the interaction of special-scientific and pedagogical thinking, is forming his/her methodical thinking. Given the importance of the work on the formation of a student's personality, a subject teacher thinks through the ways of forming humanistic attitudes of students, using natural science material. This is the essence of a teacher's professional competence. The methodological aspect of teacher thinking and thinking of an educator - are two sides of the key competency of a teacher-educator.

\section{Results and Discussions}

During the experiment we were considering the possibility of forming professionally oriented thinking, integrating the characteristics of special-scientific and scientific-pedagogical thinking in the context of the major 
stages of learning activities. All the problematic case studies, which were systematically addressed by our students, had been focused on mastering the holistic teaching. This process is illustrated in terms of teaching physics and chemical-biological disciplines to students of 1-4 courses. The material was selected so that when detecting the essence of a natural science phenomenon or a fact and explaining them by resolving a number of the identified contradictions, there was the pronounced specificity of special-scientific thinking appearing (e.g., ability to think in terms of contradictions between stability and variability, to use physical or chemical theory as a knowledge method).

\subsection{Criteria of the Professional Thinking Basic Characteristics Formation}

The formation criteria of students' basic characteristics of professional thinking are the diagnosed logic skills based on the special-subject material (six evaluation criteria have been selected), skills related to mastering a research method applied to professional-subject problems (five evaluation criteria) and solutions of logic-methodological problems specific to teacher education (six evaluation criteria). Consideration of the corresponding abilities-criteria allows exploring new intellectual formations in the form of revealed by a future teacher ways to solve a problem, formulated on the basis of analyzing the contradiction, which had created the subject-pedagogical problem situation.

In addition to the differentiated determination of expected shifts in the relevant skills of students there is the estimation of the expected shifts of interest in their complex manifestations. As such an integral indicator (in this case in physics or chemical-biological disciplines) - an integral special-subject indicator (ISSI) can be accepted. The integral special-subject indicator (ISSI) - is the average indicator of basic characteristics of professional thinking of a teacher (logical thinking, mastery of research method, solution of logic-methodological problems), diagnosed on the subject material.

\subsection{Levels of the Basic Characteristics Formation}

The research materials allowed allocating the following levels of the basic characteristics of professionally oriented thinking: high, medium, low, very low (the characteristic of levels for each of the 17 considered abilities is provided). In the experiment there were two groups of students involved - the control and the experimental (in total, including questionnaires, 519 people) and more than 500 students at the stage of the searching didactic experiment. In the qualitative and quantitative analysis of the results of the experimental study to test the statistical hypotheses the median criterion was used (for the significance value of $\alpha=0.05$ and single degree of freedom).

\subsection{Stages of the Experimental Work}

Preparation and organization of the experimental work included the stages: preliminary, initial diagnosing, formative didactic and final diagnosing. The purpose of the preliminary stage: 1) preparation of the experimental material necessary for the subsequent stages; 2 ) inspection and testing of diagnostic techniques and elements of the formative experiment. The purpose of the diagnostic stage: get an objective picture of the baseline level status of the basic characteristics of professional thinking and its integral special-subject indicator of 1-4 courses students, who are going to become teachers of natural science subjects (physics, chemistry and biology).

\subsection{Methods of the Experiment}

In accordance with the set objective the statistical methods for processing the results of the experimental study were used. We carried out the grouping of data according to their values, the arrangement of frequency distribution of these values, the grouping of the obtained data by intervals. First the marked procedures of the descriptive statistics were used to obtain an objective picture of the basic characteristics' baseline level status of professional thinking (logical thinking, mastery of research method, solution of logic-methodological problems). Then the objective picture of the ISSI baseline level status of professional thinking was similarly revealed in the experimental and control groups (EG and CG).

\subsection{The Experimental Results}

The initial diagnosing stage showed that in EG and CG before the experiment the students - prospective teachers of biology and chemistry had the low level dominant of both-logical thinking (respectively $56.4 \%$ and $46.4 \%$ ), and mastering the research method $(74.5 \% \mathrm{EG}$ and $75.0 \% \mathrm{CG})$ and of solving logic-methodological problems $(58.2 \% \mathrm{EG}$ and $55.3 \% \mathrm{CG})$, and in the future teachers of physics, generally-medium plus low levels: logical thinking $(51.0 \%+13.4 \%)$ EG and $(50.0 \%+29.6 \%)$ CG; mastery of research method $(37.3 \%+52.9 \%)$ EG and $(44.4 \%+42.6 \%) \mathrm{CG}$; solutions of logic-methodological problems $(35.3 \%+54.9 \%)$ EG and $(44.4 \%+48.2 \%)$ CG. There were no significant differences found in the levels of the basic characteristics of professional thinking development, as well as its ISSI in students of experimental and control groups. 
During the didactic experiment from the analysis of the intermediate results there were two key points found. Firstly, it is the possibility of the gradual formation of the fundamental characteristics of professional thinking of students - the gradual transfer of students from one level to another, a higher one. Secondly, it is the beginning of the formation of professionally-oriented thinking of the prospective teachers of natural science subjects - junior courses, starting to learn fundamental disciplines of the profession-oriented training using the material of these disciplines.

The final diagnosing stage revealed significant shifts and differences in EG and CG on the levels of the basic characteristics formation and the ISSI of students' professional thinking (future biology and chemistry teachers-table 1, 2; future physics teachers-figure 1-4).

Table 1. The average values of the qualities level and basic characteristics of students' professional thinking in experimental and control groups

\begin{tabular}{|c|c|c|c|c|c|c|c|c|}
\hline \multirow[t]{2}{*}{$\begin{array}{l}\text { Qualities } \\
\text { characterizing logical } \\
\text { thinking (level of...) }\end{array}$} & \multicolumn{2}{|c|}{$\begin{array}{l}\text { Average } \\
\text { values of } \\
\text { the level }\end{array}$} & \multirow{2}{*}{$\begin{array}{l}\text { Qualities characterizing } \\
\text { mastery of the research } \\
\text { method } \\
\text { (level of...) }\end{array}$} & \multicolumn{2}{|c|}{$\begin{array}{l}\text { Average } \\
\text { values of } \\
\text { the level }\end{array}$} & \multirow{2}{*}{$\begin{array}{l}\text { Qualities characterizing the } \\
\text { ability to } \\
\text { logic-methodological } \\
\text { problems (level of...) }\end{array}$} & \multicolumn{2}{|c|}{$\begin{array}{l}\text { Average } \\
\text { values } \\
\text { the level }\end{array}$} \\
\hline & EG & CG & & EG & CG & & EG & CG \\
\hline generalization & 3.56 & 3.02 & $\begin{array}{l}\text { formulating the research } \\
\text { goal }\end{array}$ & 3.60 & 2.73 & $\begin{array}{l}\text { sustained interest in solving } \\
\text { problems (motivation) }\end{array}$ & 3.62 & 2.50 \\
\hline inductive inferences & 3.53 & 3.04 & research method selection & 3.45 & 2.39 & $\begin{array}{l}\text { defining the topic to which the } \\
\text { problem pertains }\end{array}$ & 3.45 & 2.70 \\
\hline deductive inferences & 3.74 & 3.00 & $\begin{array}{l}\text { actualizing the necessary } \\
\text { knowledge }\end{array}$ & 3.31 & 2.45 & $\begin{array}{l}\text { selecting the cognitive } \\
\text { problems of the topic }\end{array}$ & 3.31 & 2.48 \\
\hline explanations & 3.20 & 2.70 & $\begin{array}{l}\text { making, substantiating, and } \\
\text { verifying a hypothesis }\end{array}$ & 3.18 & 2.21 & $\begin{array}{l}\text { theoretical } \\
\text { application }\end{array}$ & 3.27 & 2.30 \\
\hline logic errors & 3.09 & 2.39 & $\begin{array}{l}\text { presenting the research } \\
\text { results }\end{array}$ & 3.40 & 2.48 & $\begin{array}{l}\text { logic and explanation of } \\
\text { problem solution methodology }\end{array}$ & 3.05 & 2.34 \\
\hline evidence & 2.91 & 2.21 & & & & $\begin{array}{l}\text { critical self-assessment of the } \\
\text { performed task }\end{array}$ & 3.85 & 2.84 \\
\hline \multicolumn{9}{|c|}{ Average values of the fundamental characteristics level of professional thinking: } \\
\hline logical thinking & 3.34 & 2.73 & the research & 3.39 & 2.45 & $\begin{array}{l}\text { logic-methodological problem } \\
\text { solutions }\end{array}$ & 3.42 & 2.53 \\
\hline The integral special-subjec & indica & or level & f professional thinking & & & & 3.38 & 2.57 \\
\hline
\end{tabular}



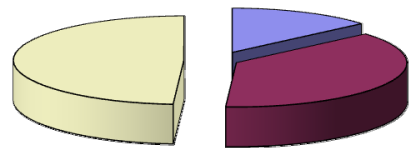

Figure 1. Distribution of the students in the experimental group on the ISSI levels of professional thinking at the initial diagnostic stage

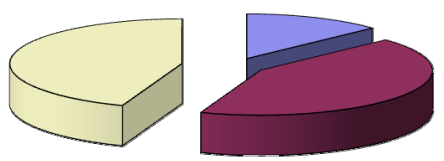

Figure 3. Distribution of the students in the control group on the ISSI levels of professional thinking at the initial diagnostic stage

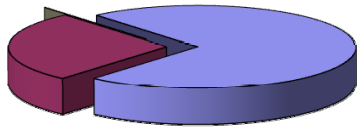

Figure 2. Distribution of the students in the experimental group on the ISSI levels of professional thinking at the final diagnostic stage

high level,

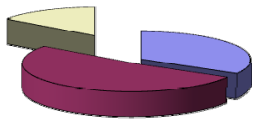
$33,3 \%$

Figure 4. Distribution of the students in the control group on the ISSI levels of professional thinking at the final diagnostic stage

Table 2. Dynamics of distributing the students on the individual qualities levels of the professional thinking basic characteristics

\begin{tabular}{|c|c|c|c|c|c|c|c|c|}
\hline \multirow[t]{2}{*}{$\begin{array}{l}\text { Criteria of the logical } \\
\text { thinking level }- \text { the } \\
\text { ability to ... }\end{array}$} & \multicolumn{2}{|c|}{$\begin{array}{l}\% \text { of students } \\
\text { who } \\
\text { improved } \\
\text { their abilities }\end{array}$} & \multirow[t]{2}{*}{$\begin{array}{l}\text { Criteria of the research } \\
\text { method mastery } \\
\text { level - the ability to ... }\end{array}$} & \multicolumn{2}{|c|}{$\begin{array}{l}\% \text { of students } \\
\text { who } \\
\text { improved } \\
\text { their abilities }\end{array}$} & \multirow[t]{2}{*}{$\begin{array}{l}\text { Criteria of the } \\
\text { logic-methodological problems } \\
\text { solution level—-the ability to ... }\end{array}$} & \multicolumn{2}{|c|}{$\begin{array}{l}\% \text { of students } \\
\text { who } \\
\text { improved } \\
\text { their abilities }\end{array}$} \\
\hline & EG & $\mathrm{CG}$ & & EG & $\mathrm{CG}$ & & EG & $\mathrm{CG}$ \\
\hline generalize & 80.0 & 48.2 & $\begin{array}{l}\text { formulate the research } \\
\text { objective }\end{array}$ & 100 & 76.8 & $\begin{array}{l}\text { manifest a sustained interest in } \\
\text { solving problems (motivation) }\end{array}$ & 89.1 & 5.4 \\
\hline $\begin{array}{l}\text { make } \\
\text { inferences }\end{array}$ & 50.9 & 19.6 & select a research method & 94.5 & 53.6 & $\begin{array}{l}\text { define the topic, to which the } \\
\text { problem pertains }\end{array}$ & 89.1 & 66.1 \\
\hline $\begin{array}{l}\text { make } \\
\text { inferences }\end{array}$ & 89.1 & 53.6 & $\begin{array}{l}\text { actualize the necessary } \\
\text { knowledge }\end{array}$ & 98.2 & 60.7 & $\begin{array}{l}\text { single out cognitive problems of } \\
\text { the topic }\end{array}$ & 92.7 & 57.1 \\
\hline $\begin{array}{l}\text { explain facts and } \\
\text { phenomena }\end{array}$ & 70.9 & 44.6 & $\begin{array}{l}\text { make, substantiate, verify } \\
\text { a research hypothesis }\end{array}$ & 98.2 & 48.2 & apply theoretical knowledge & 96.4 & 41.1 \\
\hline find logical errors & 92.7 & 58.9 & $\begin{array}{l}\text { present the research } \\
\text { results competently }\end{array}$ & 92.7 & 51.8 & $\begin{array}{l}\text { choose the logic and } \\
\text { methodology of problem } \\
\text { solution }\end{array}$ & 94.5 & 48.2 \\
\hline provide evidence & 83.6 & 42.8 & & & & $\begin{array}{llr}\text { carry out a } & \text { critical } \\
\text { self-assessment } & \text { of } & \text { the } \\
\text { performed task } & & \end{array}$ & 80.0 & 32.1 \\
\hline \multicolumn{9}{|c|}{ There is a shift observed from one level to another: } \\
\hline logical thinking & 83.6 & 37.5 & research method mastery & 94.5 & 42.9 & $\begin{array}{l}\text { logic-methodological problem } \\
\text { solutions }\end{array}$ & 83.6 & 28.6 \\
\hline the integral special-subjec & indica & of pro & ssional thinking & & & & 89.1 & 41.1 \\
\hline
\end{tabular}


The analysis of the final stage results of the experimental work has revealed a steady tendency towards significant improvement in the basic characteristics indicators of students' professional thinking in the EG.

\section{Conclusions}

Thus, during and upon the completion of the experiment (in the middle and the end of every school year) the corresponding performance indicators' essential increase in the EG compared to the CG of students is established.

The use of special integrated courses aimed at the formation of professional thinking on the basis of comprehensive educational and cognitive problems; the use of optimal structuring of educational material on the natural sciences; teaching the students to know laws, forms and methods of logical thinking in the study of natural science cycle disciplines; the use of problematic situations and problem tasks based on cognitive contradictions that occur in the natural sciences; gradual training to solve professional-subject problems; organization of the activities of students in developing their ability to apply hypotheses in learning knowledge in the process of scientific knowledge acquisition in the classroom at the university; implementation of various research tasks, developing intuitive and creative thinking - all of those contributed to transferring the students from the level of formal-logical generalization on to the level of substantive generalizations, and later - on to the level of hypothetical-deductive reasoning and, accordingly, a scientific explanation and prediction of phenomena, establishing cause-and-effect relationships, ability to explain the method of solving professional/subject problems.

At the same time the research has shown that the problem of forming professional thinking of a teacher-naturalist leaves reserves to deal with particular issues and to further improve them. These issues include (given the importance of intuition in cogitative activity) a search for methods and techniques of training, in which there is an optimum combination of the intuitive and the logical components of thinking in the activities of natural sciences prospective teachers. The present research opens the way for further study, improvement and development of a new area in the didactic theory of professional training and formation of professional thinking in students of teacher education universities.

\section{Acknowledgments}

The work is performed according to the Russian Government Program of Competitive Growth of Kazan Federal University

\section{References}

Danilov, A. G. (2005). Creative pedagogy: The urge to be creative. Chemistry at school, 4, 26-29.

Fayzullina, A. R., \& Mukhametzyanova-Duggal, R. M. (2015) Multi-Confessional Societies in Russia and India: Models of Relations between the State and Religious Associations. Review of European Studies, 7(1), 12-17.

Gilmanshina, S. I. (2005). Professional thinking teacher. Higher education today, 12, 50-52.

Gilmanshina, S. I., \& Kamasina, A. R. (2013). Formation of students' value-semantic competence on the basis of the design of teaching chemistry. Alma mater, 1, 78-81.

Gilmanshina, S. I., \& Motorygina, N. S. (2013). The logical thinking in terms of innovative educational settings. Basic research, 10(2), 398-401.

Goryunova, T. A. (1981). Path to the teaching profession (p. 96). Moscow: Pedagogy.

Gromyko, Y. V. (2000). Concept and design theory in developmental education. Proceedings of radioactive waste, 2 .

Ivanov, V. G., Shaidullina, A. R., Drovnikov, A. S., Yakovlev, S. A., \& Masalimova, A. R. (2015). Regional Experience of Students' Innovative and Entrepreneurial Competence Forming. Asian Social Science, 11(1), $35-40$.

Kashapov, M. M. (2000). Psychology of professional pedagogical thinking (p. 48). Moscow.

Kashapov, M. M. (2000). Psychology pedagogical thinking: Monograph (p. 463). St. Petersburg: Publishing House of the marshmallow.

Khairullina, E. R., Valeyev, A. S., Valeyeva, G. K., Valeyeva, N. S., Leifa, A. V., Burdukovskaya, E. A., \& Shaidullina, A. R. (2015). Features of the Programs Applied Bachelor Degree in Secondary and Higher Vocational Education. Asian Social Science, 11(3), 213-217. 
Korzhuev, A. V., Popkov, V. A., \& Ryazanov, E. L. (2002). Reflection and critical thinking in the context of the tasks of higher education. Pedagogy, 1, 18-22.

Kulyutkin, U. N. (1986). Creative thinking in the professional work of the teacher. Questions of psychology, 2, 21-30.

Levina, E. Y., Saglam, F. A., Skorobogatova, A. I., Shaikhlislamov, A. K., Sagitova, V. R., \& Fayzullina, A. R. (2015) Quality Control Optimization of University Students Training. Asian Social Science, 11(2), 296-300.

Markova, A. K. (2007). Problems of development of vocational education in Russia. Education and Science, 2(44), 36-42.

Matyushkin, A. M. (2003). Thinking, learning, creativity (p. 720). Voronezh.

Merzon, E. E., Fayzullina, A. R., Ibatullin, R. R., Krylov, D. A., Schepkina, N. K., \& Pavlushkina, T. V. (2015). Organizational and pedagogical conditions of academic mobility development of students at school of higher professional education. Review of European Studies, 7(1), 46-51.

Meshkov, N. I. (2003). Learning motivation and professional thinking. Integration of education, 2, 138-141.

Mrathuzina, G. F., Fayzullina, A. R., \& Saglam, F. A. (2015) Substantive, Methodological and Organizational Discourse in Oriental History Learning at School and University. Review of European Studies, 7(1), 57-62.

Mukhametzyanova, G. V. (2006). Vocational education: The labor market and the quality of training. Kazan pedagogical journal, 4(46), 8-18.

Osipova, E. A. (2011). Axiological foundations of the theory of public relations in the context of globalization (PhD Thesis). Moscow.

Polyakov, O. O. (2003). Formation of professional thinking: The problem of universal theoretical model. Integration of education, 2, 141-145.

Sakhieva, R. G., Khairullina, E. R., Khisamiyeva, L. G., Valeyeva, N. S., Masalimova, A. R., \& Zakirova, V. G. (2015). Designing a Structure of the Modular Competence-Based Curriculum and Technologies for Its Implementation into Higher Vocational Institutions. Asian Social Science, 11(2), 246-251.

Shelontsev, V. A., Gerasimov, I. V., \& Buyanova, O. V. (2000). Using classification algorithms in teaching chemistry for the development of students' thinking. Science and school, 6, 27-31.

Sibgatova, K. I., Mirzagalyamova, Z. N., Pupysheva, E. L., Mirzanagimova, F. I., Shkinderova, I. N., Nuriyeva, E. N., ... Schepkina, N. K. (2015). The Educational Institution Teachers and Professional Community Representatives' Readiness Formation for the Joint Pupils' Career Guidance Implementation. Review of European Studies, 7(1), 74-79.

Vilkeev, D. V. (1986). Terms efficient use of scientific theories of cognitive function in the process of learning. New research in pedagogical sciences, 1(47), 7-11.

Vilkeev, D. V. (1992). Formation of pedagogical thinking in students (p. 108). Kazan: KSPU.

Vilkeev, D. V. (2001). Educational psychology: A course of lectures (p. 262). Kazan: KSPU.

Vygotsky, L. S. (2005). Educational Psychology (p. 672). Moscow: AST.

\section{Copyrights}

Copyright for this article is retained by the author(s), with first publication rights granted to the journal. This is an open-access article distributed under the terms and conditions of the Creative Commons Attribution license (http://creativecommons.org/licenses/by/3.0/). 